Maria Cristina Hennes Sampaio

\title{
ÉTICA E CIÊNCIAS HUMANAS: DIÁLOGOS FILOSÓFICOS ENTRE M.BAKHTIN E E.LÉVINAS
}

\author{
(Ethics and human sciences: philosophical dialogues \\ between M.Bakhtin and E. Levinas)
}

\author{
Maria Cristina Hennes Sampaio ${ }^{1}$ \\ (Universidade Federal de Pernambuco UFPE)
}

\begin{abstract}
This paper aims to describe the dialogue between M. Bakhtin (1993) and Emmanuel Lévinas (2009) on ethics, and find the philosophical and empirical arguments to rethink its relevance to the thinking and to the scientific practice in Human Sciences today. For this purpose we will apply the dialogical method on the discourse analysis of the authors'works. While Bakhtin suggests a moral philosophical paradigm of interpreting reality, Lévinas proposes ethics as first philosophy. The ethical dimension, for both authors, requires a new paradigm of thought and action which offers a new perspective on human otherness and its forms of expression.
\end{abstract}

key-words: ethics; human sciences; dialogical method; Bakhtin; Lévinas.

\section{RESUMO}

O presente artigo tem por objetivo explicitar o diálogo instaurado entre os filósofos M. Bakhtin (1993) e Emmanuel Lévinas (2009) acerca da ética e encontrar os argumentos filosóficos e empíricos para repensar sua pertinência para o pensamento e à prática científica nas Ciências Humanas

1. Doutora em Linguística pela USP-SP (2002), com estágio na Universidade de Provence, França, (2001); Pós-doutorado em Linguística pela PUC-SP (2012). Docente e pesquisadora do Programa de Pós-Graduação em Letras da Universidade Federal de Pernambuco. Líder do GP/CNPq/UFPE: Linguagem, sociedade saúde e trabalho. Trabalho resultante do pós-doutorado/2011-2012 junto a PUC-LAEL-SP, www.pucsp.br como bolsista pós-doutorado sênior CNPq - www.cnpq.br. 
na atualidade. Para esse fim será aplicado o método dialógico na análise dos discursos contidos em obras desses autores. Enquanto Bakhtin propõe um paradigma filosófico moral de interpretação da realidade, Lévinas vai propor a própria ética como filosofia primeira. A dimensão ética, para ambos os autores, pressupõe um novo paradigma de pensamento e de ação o qual oferece um novo olhar acerca da alteridade humana e de suas formas de expressão.

palavras-chave: ética; ciências humanas; método dialógico; Bakhtin; Lévinas.

\section{Introdução}

A ética é uma disciplina que remonta o pensamento de filósofos como Platão e Aristóteles e, desde os seus primórdios, vai se ocupar com uma série de questões ainda válidas para uma discussão filosófica e epistemológica contemporânea acerca das formas de abordagem do conhecimento científico. Nesse sentido, Bakhtin, filósofo russo, nos anos de sua juventude, escreveu um texto denominado $K$ filosofii postupka (Para uma filosofía do ato ético) (BUBNOVA, 1997) no qual vai estabelecer as bases de uma arquitetônica em torno da vida, da arte e da ciência, integrando o ético, o estético e o cognoscitivo.

Sabemos que Bakhtin leu e foi influenciado por diversos filósofos, conforme citações feitas pelo próprio autor ${ }^{2}$, em Para uma filosofía do ato ético, e já bastante referido por diversos estudiosos de sua obra (PONZIO, 2008; 2010; SAMPAIO, 2009; 2011; ZAVALA, 2009; AMORIM, 2009; SOBRAL, 2005; HOLQUIST, 1993), além daqueles filósofos ${ }^{3}$ cujas idéias, embora não estejam explícitamente referidas, estão bastante próximas às idéias bakhtinianas. É o caso do filósofo lituano, naturalizado francés, Emmanuel Lévinas, cujas idéias, em relação à categoría ética da responsabilidade/alteridade,

2. Bakhtin foi influenciado, entre outros, por Edmund Husserl, a propósito da consciência projetada no ser, pela ética formal de Immanuel Kant, pela ontologia de Martin Heidegger e pela filosofia da vida de Henri Bergson.

3. Entre as idéias filosóficas, a dialogicidade em Buber, o existencialismo em Kierkegaard, o comportamento humano em Dilthey, etc). 
Maria Cristina Hennes Sampaio

dialogam com aquelas postuladas por Bakhin no âmbito da dimensão da responsabilidade/dialogismo.

Nesse sentido, o presente artigo tem por objetivo explicitar as relações dialógicas instauradas nos postulados filosóficos, acerca da ética, em ambos os filósofos, Bajtin (1997) e Emmanuel Lévinas (2009), e levantar questões filosóficas e empíricas pertinentes para o pensamento e a prática científica nas Ciências Humanas na atualidade.

\section{Breve perfil dos autores e contexto das obras}

Bakhtin, nascido em 1895, na cidade de Orel, próxima a Moscow, era onze anos mais velho do que Lévinas, de origem judaica, nascido em 1906, na cidade de Kaunas, na Lituânia (Rússia). Bakhtin deixa sua cidade natal em 1905, quando passa a residir e a fazer seus estudos secundários na capital da Lituânia, onde permanece até 1912 aproximadamente. Nesse período viveu em um contexto plurilingue e pluriracial o que viria a influenciar, anos mais tarde, sua produção teórico-conceitual. Foram anos de efervescência política, estética e religiosa que antecederam a Revolução de 1917. Foi em 1913, já na cidade ucraniana de Odessa que ele vai ter o contato com a leitura do filósofo austríaco Martin Buber. Inicia sua formação em 1914, em estudos clássicos, na Universidade de São Petersburgo. A partir de 1918 passa a residir e trabalhar em Nevel, como professor de História, Sociologia e Russo, onde vai participar ativamente do Seminário Kantianano de Nevel, também denominado de Primeiro Círculo, juntamente com vários outros intelectuais, entre eles, Voloshinov. Politicamente é o período no qual se instala o comunismo na Rússia, sob o domínio bolchevique. Em 1919 Bakhtin publica o artigo Arte e Responsabilidade que só viria a ser republicada uma década mais tarde, em 1970. Em 1920, com vários membros do Círculo já transferidos para a cidade de Vitebsk, próxima a Nevel, Bakhtin vai ensinar Literatura e História da Filosofia da Música, dando continuidade à escritura de seu grande projeto - A arquitetônica da Responsabilidade -, do qual foram recuperados os fragmentos de $O$ autor e o herói e 
Por uma filosofia do ato. Entre 1924 e 1929, já em Leningrado, foram escritas quatro importantes obras: O Freudismo (1927), assinado por Voloshinov, O método formal nos estudos literários (1928), assinado por Medvedev, Marxismo e filosofia da linguagem (1929), assinado por Voloshinov, e Problemas da obra de Dostoiévski (1929) de Bakhtin (BRAIT e CAMPOS, 2009).

Os estudos filosóficos de Lévinas foram iniciados em 1923, já na cidade de Estrasburgo (França), onde se radicou com sua família. Foi discípulo de Edmundo Husserl, entre 1928-9 e influenciado pela sua obra Investigações Lógicas ${ }^{4}$ e, mais tarde, tornou-se um seguidor de Heidegger ${ }^{5}$ que afetou profundamente seu pensamento com a obra O ser e o tempo (EDU/LIBRARY, 2010). Lévinas também foi influenciado pelo filósofo francês Henri Bergson, o qual considerava o precursor do pensamento acerca do rosto, destacando-se a obra bergsoniana Ensaio sobre os dados imediatos da consciência ${ }^{6}$, reveladora da experiência do espírito e da prioridade ética conferida à espiritualidade do Outro (TAMINIAUX, 2008). A partir dos anos 50 ele começa a formular suas própria idéias filosóficas acerca do primado da relação ética com o Outro. Enquanto Heidegger ocupou-se com o Ser, Lévinas faz uma distinção entre ética e ontologia, voltando sua atenção para aquilo que está além do Ser em sua transcendência, exterioridade e infinitude - o Outro (EDU/ LIBRARY, 2010).

\section{Princípios da ética e da bioética: implicações para a prática científica nas Ciências Humanas}

De uma maneira geral pode-se dividir a ética em domínios do conhecimento: a metaética - que trata, em princípio, de questões

4. A obra foi escrita entre 1900-1901.

5. A primeira edição, em alemão, Sein und Zeit, foi publicada em 1927 pela editora Max Niemeyer Verlag, Tübingen (antes Halle).

6. A obra foi escrita em 1889 sob o título Essais sur les données immédiates de la conscience. 
Maria Cristina Hennes Sampaio

de natureza filosófica da ética. Aquí entrariam temas relativos à natureza dos juízos e valores morais, regras, qualidades morais (virtudes). A ética normativa, utilizada na bioética, determina, com base em pressupostos da metaética, princípios e normas gerais de ação aplicáveis, por exemplo, à pesquisa científica com seres humanos. Ela expressa o código moral e as leis próprias de uma investigação científica, compreendendo o seu direcionamento teórico-metodológico e os procedimentos. A ética prática consiste na aplicação dos resultados da ética normativa em problemas do cotidiano que envolvam questões de orden moral (BELLINO, 1997).

Quanto à bioética, segundo definição da Encyclopedia of Bioethics (REICH apud BELLINO, 1997:21), refere-se ao "estudo sistemático do comportamento humano na área das ciências da vida e dos cuidados da saúde, quando se examina esse comportamento à luz dos valores e os princípios morais." Seu objeto material é a vida em sentido amplo: "vida humana pessoal e não-pessoal", incluindo "todos os organismos capazes de sentir prazer e/ou dor e também o ambiente em geral” (BELLINO, 1997:34).

Com as conquistas científicas e biomédicas ampliaram-se as possibilidades de intervenção e manipulação na vida do homem, o que justifica a exigência rigorosa da avaliação ética de tais intervenções a fim de garantir o respeito a sua dignidade e autonomia (BELLINO, 1997).

Nesse sentido, toda a pesquisa só se justifica eticamente se for realizada de tal maneira que respeite e proteja os sujeitos dessa pesquisa, seja justa para eles e moralmente aceitável nas comunidades em que é realizada (CIOMS, 2004:37).

Quanto à pesquisa, nas Ciências Humanas, que lida com seres humanos, cabe salientar que esta é disciplinada pelos mesmos princípios gerais que orientam a matéria em relação às pesquisas no âmbito da saúde, o que na prática científica tem gerado muitas controvérsias e incompreensões. Quando se trata de pesquisas no âmbito da análise da linguagem, do discurso e da comunicação, por exemplo, argumenta-se que estas não ofereceriam nenhum risco aos sujeitos, já que a pesquisa 
não teria por objeto os sujeitos ${ }^{7}$ em si mesmos e sim o estudo dos discursos proferidos por eles de forma não consciente. De forma semelhante, quando se avalia, por exemplo, no projeto de pesquisa, a forma de devolução dos resultados aos sujeitos, argumenta-se que a pesquisa não estaria diretamente relacionada com os indivíduos que concordaram em participar, mas apenas com o tipo de expressão verbal usada por eles, sem nenhuma avaliação pessoal. Este tipo de argumentação é no mínimo estranha aos princípios ético-científicos que norteiam a pesquisa científica com seres humanos, considerandose que os sujeitos da pesquisa, nesse caso, são professores de língua que seriam observados em relação aos seus desempenhos linguísticos na prática profissional e institucional. Além disso, ainda que fosse assegurado que não haveria uma avaliação do desempenho dos falantes, parece injustificável a assertiva avaliativa, contida na alusão feita aos prováveis "benefícios", aos sujeitos, de que as observações e conclusões do trabalho poderiam servir de alerta sobre determinados vícios de linguagem nos seus desempenhos profissionais e auxiliá-los na utilização de uma expressão linguística de qualidade. Com relação ao exemplo citado, muitas questões de natureza ético-científicas podem ser levantadas. Seria eticamente aceitável, numa pesquisa dessa natureza, isolar a linguagem e o discurso do sujeito, alegando tratar-se apenas de um material linguístico produzido por falantes de forma inconsciente? Além disso, do ponto de vista metodológico, como seriam obtidos tais dados dos sujeitos designados como meros "informantes", ainda que se assegurasse o sigilo de suas identidades? Da mesma forma como se coleta um material biológico de um sujeito para análise científica? A coleta de dados de seres humanos, sejam eles de natureza linguística (discursiva) ou biológica (amostras de material humano), não implicaria sempre em procedimento invasivo da privacidade e do corpo físico e psíquico dos sujeitos, quer estejamos falando do ponto de vista subjetivo como fisiológico? Qual a finalidade desta coleta? Qual a finalidade desta pesquisa? Quais os benefícios diretos para os sujeitos? Quais as garantias de não maleficência? Quais

7. Os sujeitos, nesse caso, são considerados "meros informantes". 
Maria Cristina Hennes Sampaio

as garantias de proteção à dignidade? $\mathrm{O}$ que, nesse caso, significa dignidade, quando a priori já se antecipa uma avaliação discriminatória em relação a esses sujeitos?

Como sugere Bellino (1997) a bioética vai muito além de um sistema particular de valores já dados que definem a categoría do bem: ela está na interdependência daquilo que ainda não é, daquilo que ainda precisa ser definido. Ou seja, a bioética tem como objeto "não já o ser mas o não ser do homem: o que ainda não é, o que se poderia fazer, ou se discute se é humano [...].” (BELLINO, 1997:28). Nesse sentido, ela é ainda um campo em aberto para se repensar a dimensão dos valores humanos. Além disso, como pondera Bellino (1997:35), na avaliação bioética há necessidade de se fazer a distinção de pelos menos três níveis de problemas - metafísicos (ou conceituais) ${ }^{8}$, empíricos (ou científicos) e valorativos (ou éticos) -, para evitar o dogmatismo científico ingênuo e o tecnicismo que acreditam poder oferecer respostas para problemas envolvendo definições como "vida”, "morte", "humano" através "da mera constatação empírica, técnica dos eventos", enquanto o problema definidor não pode ser resolvido empiricamente, já que necessitamos da definição teórica para interpretar as experiências empíricas.

\section{Método dialógico de abordagem do pensamento moral e ético em Bakhtin e Lévinas}

Nossa abordagem de análise consiste em evidenciar as relações de sentido estabelecidas entre os enunciados concretos e os discursos contidos nas obras em questão e levantar algumas questões pertinentes para o pensamento e o fazer científico nas Ciências Humanas.

Considerando que a expressão do pensamento participativo, como ato responsável, é materializada na palavra, o que equivale

8. Entrariam aqui, por exemplo, problemas "relacionados às questões últimas (Deus, imortalidade da alma, etc)" e "a análise conceitual das noções de pessoa, eu, morte, tempo, vida.” (BELLINO, 1997:35) 
dizer, no texto e no discurso, a abordagem do ser-evento que nos ocupa - a Ética e a Pesquisa Científica nas Ciências Humanas -, só pode ser realizada na perspectiva de uma ação dialógica como um ato responsável. Ora, sabemos que o dialogismo, enquanto pressuposto conceitual-analítico, pressupõe o estabelecimento de relações de sentido. E o que é o mundo do conteúdo-sentido para Bakhtin? É um mundo no qual não há espaço para o Ser como algo determinado, válido em si mesmo, como uma verdade fundadora de um "começo" do sentido. Ao contrário, é um mundo que não oferece um "começo", um princípio de escolha do sentido: "apenas a infinidade da avaliação e absoluta inquietação são possíveis" na perspectiva do reconhecimento de minha participação única no Ser" (BAJTIN, 1997:50). Por conseguinte, uma ação dialógica como ato responsável - resultante da auto-atividade de dever-ser -, deve orientar-se para um conteúdosentido que só pode ser desvelado no Ser-evento e através do reconhecimento de nossa participação única no Ser.

Nesse contexto, ao contrapor as abordagens da cognição teórica e da intuição estética para a compreensão do ser-evento - com as quais dialoga exaustivamente ao longo de seu texto -, Bajtin (1997) destaca que nenhuma delas oferece uma abordagem do Ser real e único de um evento, já que não há, de fato, interpenetração entre o conteúdo-sentido (produto) e o ato (uma ação histórica real), devido a própria abstração que o sujeito faz de si mesmo, enquanto participante do processo de afirmar significado e visão. Assim, aponta, como uma possível alternativa para dar conta dessa tarefa, o materialismo histórico, pelo seu esforço em tentar sair do mundo teórico abstrato e adentrar no mundo vivo da ação responsável realmente realizada (BAJTIN, 1997).

\section{As obras em questão}

As obras escolhidas, para a nossa análise, são as traduções do russo para o espanhol de Hacia una filosofia del acto ético, De los boradores y otros escritos (Rubi/Barcelona: Anthropos), de 
Maria Cristina Hennes Sampaio

Mijail M.Bajtin $\left(1997^{\circ}\right)$, por Tatiana Bubnova, e do francês para o português, de Entre nós. Ensaios sobre a alteridade (Petrópolis: Editora Vozes), de Emmanuel Lévinas (2009), por Pergentino Stefano Pivatto. Estima-se que a obra bakhtiniana tenha sido escrita entre 1920-1924, embora não tivese sido preparada para publicação, conforme assinala a tradutora Bubnova (1997, p. XIV), pois fazia parte "de um grande projeto de uma prima philosophia, em forma de uma filosofía moral": "o mundo em que um ato é realizado orienta-se sob a base de sua participação única no Ser - este é o objeto da filosofía moral” (BAJTIN, 1997:60). Já a primeira edição do livro de Lévinas apareceu em Paris em 1991, pela Editora Grasset Fasquelle, sob o título Entre nous. Essais sur le penser-à-l'autre na qual o autor vai propor a própria ética como filosofia primeira, retomando o conceito do Ser como processo ou acontecimento de Ser na dimensão da alteridade, dedicando-se à análise intersubjetiva da relação de um-(mesmo)para-o-outro (nós) que instaura o sujeito ético e o acontecimento ético (LÉVINAS, 2009).

\section{Abordagem teórica da dimensão ética do pensamento enquanto ato}

Considerando que o nosso objeto de estudo compreende o pensamento ético contido nas obras referidas, partimos do pressuposto bakhtiniano de que a ética só pode ser compreendida através do ato individual e único de pensar tais pensamentos por parte de um sujeito-pesquisador, necessariamente em relação de alteridade com outros pensamentos e contextos, já que Bajtin (1997) deixa claro que a dimensão ética de um pensamento só pode ser alcançada quando um sujeito histórico assume a responsabilidade de pensá-lo, de valorá-lo, de assiná-lo, de reconhecê-lo como seu e de responder por ele. Somente assim o pensamento será validado como ato. Em termos metodológicos isso significa dizer que todo o ato responsável pressupõe

9. A tradução da publicação, em língua portuguesa, foi feita por Valdemir Miotello, sob o título Para uma filosofia do ato responsável, São Carlos: Pedro e João Editores, 2010. 
o dever, do sujeito-pesquisador, de pensar veridicamente, já que o dever ser é uma categoria peculiar de proceder do ato ético. No plano da abordagem desse pensamento (as obras em questão) o dever ser é operacionalizado através do procedimento de correlação da verdade (daquilo que já foi dado a conhecer de um pensamento), a qual é reconhecida e validada por uma comunidade científica, com o ato autêntico de conhecimento e historicamente único por parte do sujeito- pesquisador, exatamente do lugar que ocupa na vida de um ser-evento como acontecimento. Entramos aqui, diferentemente do que ocorre em relação à abordagem de um objeto de investigação, pelos métodos tradicionais da pesquisa científica, na dimensão axiológica (valorativa) atribuída a um pensamento pelo sujeito que pensa, que entona esse pensamento. É somente através do procedimento derivado do dever-ser, de minha auto-atividade de encarnar na experiência vivida de um pensamento pelo qual assumo inteira responsabilidade e em relação ao qual expresso meu tom emocional-volitivo, que esse pensamento irá adquirir sentido, ou seja, o pensamento será repleto de entonação, será um pensamento vivo, não indiferente. Este pensamento participativo transcorre dentro da arquitetônica do Ser, enquanto acontecimento ${ }^{10}$, enquanto possibilidade de vir-a-ser. A referência à arquitetônica, no pensamento bakhtiniano, como observa Amorim (2009:32;36), remete necessariamente à dimensão axiológica de um ser-evento, quer estejamos falando de uma obra de pensamento ou estética. O princípio de alteridade, do confronto entre os valores do eu e do(s) Outro(s) também abre espaço para a possibilidade da dúvida do sujeito em relação ao reconhecimento de seu ato de pensamento, pois é ela que permite que o sujeito confronte posicionamentos e valores e não seja absorvido pelo pensamento teórico que se pretende verdade universal (AMORIM, 2009). Amorim (2009) chama a atenção para o fato de estarmos vivendo, na pós-modernidade, a cultura da ação e não do ato responsável. Em relação à ação, destaca que a mesma pode ser técnica e tática. No primeiro caso, ela está a serviço da solução de proble-

10. Este ser-acontecimento só pode encontrar sua forma de expressão nas categorias de comunicação real do ato ético, de uma vivência participativa na singularidade concreta do mundo. 
Maria Cristina Hennes Sampaio

mas e demandas da vida cotidiana do homem moderno. No segundo, ela atua como mecanismo de combate e destruição do Outro. Bajtin (1997) assegura que a palavra é a expressão do Ser-evento único e unitário no qual esse ato é realizado: "seu aspecto de conteúdo (a palavra como conceito) tanto quanto seu aspecto palpável-expressivo (a palavra como imagem) e seu aspecto emocional-volitivo (a entonação da palavra) em sua unidade" (BAJTIN,1997: 39). Ao afirmar que uma "palavra viva, completa, não conhece um objeto como algo totalmente dado", Bajtin (1997:40-41) quer dizer que, pelo simples fato de ser pronunciada, ela já recebe uma entonação que expressa nossa atitude valorativa em relação ao objeto, daquilo que ainda está para ser determinado nele, fazendo dele "um momento constituinte do evento vivo em processo". Isso significa que o valor do conhecimento (conteúdo) produzido através da teoria (cognição abstrata) é diferente de um conteúdo produzido pela experiência vivida: o primeiro corresponderia a um valor dado, presumido, e o segundo ao valor afirmado por aquele que pensa de uma maneira emocional-volitiva. Trata-se de um pensamento que age, que entona, circunscrevendo todo o conteúdo-sentido no ato executado, relacionando-o ao ser-evento único. E, assim procedendo, procura expressar a verdade de um todo, de um dado momento, em sua unicidade irrepetível (BAJTIN, 1997:41;44-45). Acerca da verdade de um pensamento responsável, o ato coloca diante de si sua própria verdade como algo-a-ser-alcançado - uma verdade que une o momento do que é universal (válido universalmente) e o momento do que é individual (real). Além disso, a diferença provocada pela contraposição da singularidade de nosso ato e a sua não coincidência com o ato singular de outros sujeitos, também é lugar de produção de sentido e pode provocar a complementação do ser do outro, daquilo que ele mesmo não é capaz de enxergar em si mesmo (AMORIM, 2009). Isso não significa, no entanto, que o outro acate e/ou valide necessariamente esse excedente de visão (pensamento) do outro sem submetê-lo a uma avaliação a partir de uma autoconfrontação com o mundo teórico e o mundo da vida e da cultura habitados por outros sujeitos e formas de pensamento, nos quais poderá encontrar outros parâmetros de comparação e de contestação. Com isso quero dizer que o exceden- 
te de visão do outro sobre o $e u$, embora possa ter a pretensão de ser verdadeiro (real), não é necessariamente válido, pois se assim fosse, seríamos todos reféns da avaliação alheia. Isto significa que sua validação está na dependência de uma avaliação intersubjetiva do sujeito, objeto desse excedente de visão do outro, no mundo dos atos vividos e da cultura e de sua contraposiçaõ/identificação/reconhecimento no mundo da abstração teórica. Como sintetiza Amorim (2009:36), “o ato é ato no confronto com outros atos, de outros sujeitos" e "o sentido de um pensamento é a sua entonação” (AMORIM, 2009:24).

\section{Filosofia moral (Bakhtin) e ética (Lévinas): abordagem do conhecimento e produção do sentido}

Que aproximações podem ser feitas entre a filosofia moral de Bakhtin e a Filosofia ética de Lévinas? Que efeitos de sentido tais relações dialógicas provocam? Do ponto de vista prático, quais suas implicações para o pensamento e a prática científica nas Ciências Humanas?

Ainda que Lévinas, onze anos mais jovem do que Bakhtin, pelas circunstâncias e trajetória histórica de sua vida, aparentemente não tenha entrado em contato direto com o pensamento filosófico de seu antecessor, sabemos que ambos foram leitores do filósofo alemão Martin Heidegger, que se notabilizou pela obra Ser e Tempo, e do escritor russo Dostoiévski, além de terem sofrido forte influência da fenomenologia do matemático e filósofo alemão Edmund Husserl.

Considerando a problemática muitas vezes observada, na prática da pesquisa científica, envolvendo seres humanos, nas Ciências Humanas, de se tentar dissociar linguagem - sujeito - sentido, optamos por fazer uma análise acerca da dimensão moral/ética, na perspectiva da responsabilidade/alteridade bakhtiniana e da responsabilidade/ alteridade levinasiana, esperando levantar algumas questões éticas pertinentes para o pensamento e o fazer científico nas Ciências Humanas na atualidade.

Em algumas passagens das referidas obras pode-se observar, no pensamento filosófico de Bakhtin (1997) e Lévinas (2009), os acentos 
Maria Cristina Hennes Sampaio

apreciativos atribuídos à linguagem, como forma não apenas de expressão do pensamento participativo e do ato, como também do pensamento abstrato, como lugar no qual se inscrevem a historicidade e a responsabilidade de dizer, de responder por, de assumir a autoria do ato, de imprimir, ao ato de nosso pensamento, uma entonação valorativa.

Historicamente a linguagem foi se formando a serviço do pensamento participativo e do ato e [...] somente no dia de hoje, de sua história, foi colocada a serviço do pensamento abstrato. Para expressar [...] o ato ético e o acontecimento singular do ser [...] requer-se toda a plenitude da palavra: a unidade de seu aspecto de conteúdo semántico (palavra como conceito), de seu lado expressivo e ilustrativo (palavra como imagem), assim como a entonação emocional e volitiva. (BAJTIN, 1997:39)

Eis o ser como má questão, mas também à questão de ter de responder - nascimento da linguagem na responsabilidade; ter de falar, ter de dizer eu, ser na primeira pessoa. Ser eu precisamente; mas, por isso, na afirmação de seu ser de mim, ter de responder pelo seu direito de ser (LÉVINAS, 2009:192).

Nesse sentido, a entonação que um sujeito confere ao seu pensamento expressa seus valores os quais se contrapõem aos valores de outros pensamentos, expressos por outros sujeitos, em um dado contexto. Podemos falar, portanto, de múltiplos centros de valores e de sujeitos que participam do ser-evento os quais expressam as visões de diferentes mundos. E é em relação ao confronto dessa multiplicidade de valores que o sujeito deve responder com seu(s) ato(s) responsável(eis) (AMORIM, 2009).

Abordagem semelhante encontramos em Lévinas (2009), ao colocar em xeque a forma de conhecimento obtida ao se fazer coincidir a representação de pensamentos diversos de uns e de outros a qual resultaria invariavelmente num tipo de pensamento e discurso racional. O autor (LÉVINAS, 2009) também questiona se a linguagem só seria significativa no seu dito e em tudo que pode ser escrito, ou se não seria "significativa também na socialidade do dizer, na responsabilidade por outrem"? 
$\mathrm{O}$ que diferencia as propostas de abordagem do conhecimento do mundo, de Bakhtin e Lévinas, em relação à ciência tradicional, é a forma pela qual o sentido é produzido. Para o primeiro, o sentido de um pensamento é encontrado na sua entonação expressiva, pois como ressalta o autor (BAJTIN, 1997), no momento em que a palavra viva é pronunciada ela já está impregnada de nossa atitude valorativa em relação ao seu objeto, daquilo que ainda está para ser determinado nele, fazendo dele "um momento constituinte do evento vivo em processo" (BAJTIN, 1997:40-41). Isso significa que o valor do conhecimento (conteúdo) produzido através da teoría (cognição abstrata) é diferente de um conteúdo produzido pela experiência vivida: o primeiro corresponderia a um valor dado, presumido, e o segundo ao valor afirmado por aquele que pensa de uma maneira emocional-volitiva. Trata-se de um pensamento que age, que entona, circunscrevendo todo o conteúdo-sentido no ato executado, relacionando-o ao serevento único. E, assim procedendo, procura expressar a verdade de um todo, de um dado momento, em sua unicidade irrepetível (BAJTIN, 1997:41;44-45).

Não obstante, Bajtin (1997) assegura que ambas as formas de abordar o conhecimento não são excludentes. Ao contrário, elas se complementam na medida em que, para afirmar um pensamento (vivo), como verdadeiro, é preciso situá-lo em alguma unidade teórica, ou seja, reconhecer a sua forma de existência no todo do conhecimento universal. Tomemos um exemplo referido pelo próprio Bajtin (1997) acerca da definição do conhecimento universal de que todo o homem é mortal. Tomamos consciência de nossa mortalidade através do pensamento científico (biológico), religioso (teológico), etc, mas o fato de reconhecermos esse pensamento como verdadeiro é insuficiente para compreendermos seu sentido no mundo dos atos vividos, pois a experiência da morte, da finitude da vida, só pode ser validada na forma como eu vivencio este ser-evento enquanto acontecimento em minha única vida e na dos outros.

Da mesma forma em Lévinas (2009; 2010) o sentido só pode nascer na responsabilidade do eu pelo outro, na manifestação de sua socialidade como alguém único cujo conhecimento não pode ser 
Maria Cristina Hennes Sampaio

reduzido ou deduzido de um conjunto social que se revela ao eu em sua singulariade enquanto rosto, enquanto manifestação inesgotável do seu modo de ser:

O rosto é significação, e significação sem contexto. Quero dizer que outrem, na retidão do seu rosto, não é uma personagem num contexto. (...) Ele é o que não se pode transformar num conteúdo, que o nosso pensamento abarcaria; é o incontível, leva-nos além. Eis por que o significado do rosto o leva a sair do ser enquanto correlativo de um saber. (LÉVINAS, 2010:70)

E o que é o sentido senão o conhecimento que buscamos nas Ciências Humanas através dos textos que o ser humano produz? Daí o papel da linguagem para a expressão do Ser-evento único e unitário no qual um ato é realizado (BAJTIN, 1997), e do rosto do outro, enquanto manifestação inesgotável do ser do outro, em sua potencialidade criativa de ser sempre outro, do "seu modo histórico de ser sujeito” (LÉVINAS, apud RUIZ, 2008:144).

\section{0 conhecimento do Ser: ato ético, responsabilidade, unicidade e alteridade}

Para entendermos os enunciados concretos, contidos no pensamento filosófico de Bakhtin e Lévinas, faz-se necessário retornar à Ontologia e à Fenomenologia que se ocuparam com as questões relativas ao conhecimento do Ser. Para a primeira, a compreensão do Ser remete à própria existência do ser humano, condição para o conhecimento do homem:

O homem inteiro é ontologia. Sua obra científica, sua vida afetiva, a satisfação de suas necessidades e seu trabalho, sua vida e sua morte se articulam, com um rigor que reserva a cada um destes momentos uma função determinada, a compreensão do ser ou a verdade (LÉVINAS, 2009:22) 
Já Bakhtin (apud LAPUNOV, 1993:xii-xiii), retomando a idéia de Husserl (apud PAIVA, 2005) sobre a questão da consciência projetada no Ser, postula que o Ser está presente em uma "consciência ${ }^{11}$ viva como um evento [em processo]", "em processo de real devir”, da mesma forma que "uma consciência viva orienta-se e vive nele (no Ser) como em um evento [em processo]".

Outros conceitos-chave para a compreensão da linguagem como forma de expressão do ser-evento, como um acontecimento em processo de vir-a-ser (BAJTIN, 1997) e do Ser, como o homem por inteiro (LÉVINAS, 2009), são o pensamento participativo, ato (ético) e a unicidade/singularidade do Ser. Nesse sentido ambos os filósofos são unânimes em criticar o racionalismo/teoricismo enquanto formas de pensamento de validade universal. Em contraposição a esse pensamento universalizante Bajtin (1997) propõe o ato ético responsável ${ }^{12}$, fundamentado na seguinte pergunta: "Como posso, [...] enquanto ser pensante e responsável pelo ato de meu raciocínio, encontrar a mim mesmo num juízo de validez universal?" Um ato ético responsável, por conseguinte, só pode resultar de um pensamento participativo ${ }^{13}$, ou seja, engajado, compromissado, interessado: um pensamento não indiferente (BAJTIN, 1997). Tal pergunta também encontra responsividade em Lévinas (2009:23), quando afirma que "pensar não é mais contemplar, mas engajar-se, estar englobado no que se pensa, estar embarcado acontecimento dramático do Ser-no-mundo".

Em relação ao "evento único do Ser” interessa a Bajtin (1997:20) compreender, de uma posição singular e única, que ocupamos na existência, as consequências de tais eventos, já que o fundamento de uma vida e de uma ação realizada é o reconhecimento da unicidade

11. Para Bakhtin/Voloshinov (1988:34-35) a consciência adquire forma e existência nos signos criados por um grupo organizado no curso de suas relações sociais.

12. Bajtin (1997) considera o pensamento, com seu conteúdo - tanto na perspectiva semântica como de uma consciência histórica singular, como um ato ético responsável que revela como nos movemos e orientamos em relação ao mundo.

13. Refere-se a "uma concepção emocional e volitiva do ser enquanto acontecer em sua unicidade concreta [...] trata-se de um pensamento performativo, no sentido de remeter ao eu enquanto ator singularmente responsável pelo ato" (BAJTIN, 1997:52). 
Maria Cristina Hennes Sampaio

da nossa participação no Ser, ou seja, assumir a responsabilidade pela sua própria unicidade, pelo próprio Ser: "este acontecimento único do Ser já não é pensado, mas sim levado a efeito real e irrevogavelmente, através de mim e dos outros".

Quanto a Lévinas (2009:240-241), a unicidade é pensada não em relação a uma ordem formal de exclusão de "um não é o outro", ou ainda, "cada um é outro para cada um", mas daquele que não se deixa substituir, o Eu que assume falar na primeira pessoa, como no exemplo, citado pelo autor (LÉVINAS, 2009:216), da personagem que Dostoievski faz falar e que diz: "eu sou o mais culpado de todos". Esta unicidade diz respeito ao indivíduo humano particular na sua perseverança em viver a vida com liberdade, embora esta também seja limitada pela liberdade dos outros, o que remete, também, à dimensão da alteridade.

Ambos os filósofos evidenciam, assim, esta convocação para assumirmos a responsabilidade de nossas ações de linguagem, sem álibi, como diria Bajtin (1997) ou sem esquivança, nas palavras de Lévinas (2009). Trata-se, pois, de uma responsabilidade constitutiva do ser humano em relação a toda a forma de pensamento expresso pela linguagem. Este argumento parece-nos suficiente para justificar a indissociabilidade entre a linguagem, produzida pelo sujeito, e o ser humano, pois, ao separá-los estaríamos também reduzindo o homem a um mero objeto, esvaziando-o de sua condição de humanidade e de sujeito histórico. Da mesma forma, se considerarmos a linguagem do sujeito como mera materialidade linguística, estaremos destituindo-a de sentido o qual nunca pode ser dado a priori (BAJTIN, 1997). Esta afirmação reforça a ideia de que não existe palavra-viva que não seja socialmente valorada, que não esteja impregnada de nossos juízos de valor, que não revele nossa identidade, que não traga consigo a marca de uma assinatura. Assim sendo, não procede igualmente o argumento de que o pesquisador vai apenas fazer uso de um material linguístico produzido por falantes de forma inconsciente e que estas palavras estarão isentas da expressão de qualquer juízo de valor. Nesse caso, trata-se, antes de tudo, do reconhecimento e do respeito a autonomia do Outro (pesquisado) por parte do pesquisador, - um dos pricípios 
básicos da bioética, segundo a qual é autônomo um ser capaz de agir livremente, ou seja, que age com intenção de querer fazer algo, com conhecimento do que faz e das consequências de suas ações e livre de influências externas (DALLAGNOLL, 2005). O reconhecimento da autonomia significa também tratar os sujeitos da pesquisa como fins e não meramente como meios, objetos de manipulação do pesquisador. Esse reconhecimento do Outro também entra em relação de sentido com os momentos axiológicos do Ser: não existe o homem em geral, como afirmou Bajtin (1997), já que, da mesma forma que eu existo, um outro particular concreto existe também. E isso toca diretamente o valor considerado mais importante na bioética: a vida, em sentido amplo, de cada um: "vida humana pessoal e não-pessoal" (BELLINO, 1997:34).

Em relação à responsabilidade de nossos atos, esta afeta tanto o sujeito pesquisado como a conduta do pesquisador em relação ao médodo e à forma de obtenção dos dados. Aqui também Bajtin (1997) é claro quanto a nossa responsabilidade com o Outro, enquanto ação produtiva que só pode advir do momento do dever-ser ${ }^{14}$ através do qual transformo um pensamento em ato:

Que eu, do meu lugar único no Ser, simplesmente veja e conheça um outro, que eu não o esqueça, que para mim, também, ele exista; [...] esta é a ação que faz o ser mais completo, a ação que é absolutamente proveitosa e nova, e que só é possível por mim. Essa ação produtiva única é precisamente o que constitui o seu momento do dever. O dever se torna possível, pela primeira vez, quando há o reconhecimento do fato do ser de uma pessoa única de dentro dessa pessoa; onde esse fato se torna um centro de responsabilidade - onde eu assumo a responsabilidade pela minha própria unicidade, pelo meu próprio ser (BAJTIN, 1997:49).”

Lévinas (2009:217), ao propor uma fenomenologia da socialidade, também nos fala sobre a nossa responsabilidade com

14. O dever ser, para Bajtin (1997), é uma "categoria” peculiar de proceder enquanto "ato" (pensamento e sentimento); é orientado pela consciência "cuja estrutura" temos de "desvelar fenomenologicamente". 
o Outro, de não deixá-lo morrer só, de respondermos pela vida do outro sob o risco de nos tornarmos cúmplices dessa morte, sugerindo formas de fazer a aproximação com o seu rosto ${ }^{15}$, uma vez que não somos seus meros contempladores, mas afetados pela sua presença:

Tentei fazer uma "fenomenologia" da socialidade, a partir do rosto do outro homem - a partir da proximidade - ouvindo, antes de toda a mímica, na sua retidão de rosto, antes de toda a expressão verbal, na sua mortalidade, do fundo desta fraqueza, uma voz que comanda: uma ordem, a mim significada, de não ficar indiferente a esta morte, de não deixar outrem morrer só; isto é, ordem de responder pela vida do outro homem, no risco de se fazer cúmplice dessa morte (LÉVINAS, 2009:217).

Em artigo publicado na obra comemorativa dos 100 anos de nascimento de Lévinas, sob o título Alteridade e Ética, Pelizzoli (2008:286-287), um dos filósofos brasileiros que participa da coletânea, observa que a evocação do Outro, nossa responsabilidade por ele, parece ser orientada pelo desejo do Outro enquanto "sentimento primordial ou compaixão, num sentido espiritual e ético", caracterizado pela "afecção do eu pela alteridade". Com relação ao conceito de rosto, o olhar do pesquisador para o rosto do Outro requer despojamento de sua vontade de dominação, pois só pode haver rosto "quando abro minha consciência e meu ser emocional para ver o invisível", estabelecendo "uma relação sem posse, sem apego" e "amorosa” com o Outro (PELIZZOLI , 2008:287).

\section{À guisa de considerações finais}

Tanto em Bajtin (1997) o eu para mim, o outro para mim e o eu para o outro, artífices da arquitetônica do mundo real do ato, como em Lévinas, o eu afirmado em sua unicidade e responsabilidade irredutível

15. O rosto entendido "como revelação do estranho e abertura do sentido ético por excelência” (PELIZZOLI, 2008:284). 
com a socialidade do outro (rosto), são interpelados permanentemente pelo dever e pela responsabilidade moral e ética, já que concretizam o Ser e o sentido da alteridade humana. Em Bajtin (1997), o ato só é ato no seu confronto com o ato de outros sujeitos. Em Lévinas, como observa Ruiz (2008), em artigo dedicado a uma re-leitura da alteridade no pensamento filosófico do autor, à luz das grandes questões e problemas que se colocam na modernidade, o reconhecimento de fato do outro só é possível através da sua própria disposição gratuita em se revelar a mim, pois não posso adentrá-lo pelo meu próprio esforço e vontade, pois isto já constituiria um ato de violência. Nesse caso, ao invés de uma revelação espontânea do outro teríamos simplesmente a sua redução a minha própria interpretação de acordo com as minhas categorias de identificação e classificação prévias. Ou seja, a alteridade é uma dimensão do Ser e só pode concretizar sua forma de existência quando se torna ato ético (BAJTIN, 1997) e quando vivenciamos uma relação com um outro que se disponha a se revelar a nós enquanto rosto (LÉVINAS, 2009).

Esse modo de se conceber a alteridade, de um lado, como uma responsabilidade que assumo, sem álibi, com o ato de meu pensamento, e sem esquivança com o outro (rosto), o qual não posso rejeitar, já que a minha própria condição de ser está em interdependência com a minha responsabilidade com ele, é que institui a dimensão ética de uma filosofia.

A dimensão ética, em ambos os autores, sugere um novo paradigma de pensamento e de ação, oportunizando um novo olhar acerca da alteridade humana e suas formas de expressão, além de oferecer importante contribuição para se pensar o papel do sujeito, da subjetividade e da intersubjetividade na pesquisa nas Ciências Humanas.

Recebido em: julho de 2012 Aprovado em: setembro de 2012 mc.hennes@hotmail.com 
Maria Cristina Hennes Sampaio

\section{Referências bibliográficas}

AMORIM, Marília. Para uma filosfia do ato: "válido e inserido no contexto". In: Brait, B. (Org.). Bakhtin, dialogismo e Polifonia. São Paulo: Contexto, 2009, pp.17-43.

BAJTIN, Mijail M. Hacia una filosofia del acto ético. De los boradores y otros escritos. Trad. Tatiana Bubnova. Rubi (Barcelona): Anthropos, 1997.

BUBNOVA, Tatiana. Prefacio de la traductora. In: Bajtin, M.M.. Hacia uma filosofia del acto ético: de los boradores y otros escritos. Rubi (Barcelona): Anthropos, 1997, pp. xiii-xx.

BAKHTIN, M., VOLOCHINOV, V.N. Marxismo e Filosofia da Linguagem. São Paulo: Hucitec, 1988.

BELLINO, Francesco. Fundamentos da bioética. Aspectos antropológicos, ontológicos e sociais. Bauru: Edusc, 1997.

BRAIT, Beth e CAMPOS, Maria Inês Batista. Da Rússia czarista à web. In: Brait, B. (Org.). Bakhtin e o Círculo.São Paulo: Contexto, 2009, pp. 15-30.

CIOMS. Diretrizes Diretrizes Éticas Internacionais para a Pesquisa Biomédica em Seres Humanos, São Paulo: Edições Loyola, 2004, 151 pp..

DALL'AGNOLL, Darlei. Bioética. Rio de Janeiro: Jorge Sahar Editor, 2005.

EDU/LIBRARY. Emmanuel Levinas (1906-1995).

http://www.egs.edu/library/emmanuel-levinas/biography. Consultado em 10.09.2011.

HOLQUIST, Michael. Prefácio. In: Bakhtin, M.M.. Para um Filosofia do ato. Texto completo da edição americana Toward a Philosophy of the Act. Trad. Carlos Alberto Faraco e Cristovão Tezza. (Versão exclusiva para fins didáticos e acadêmicos). Austin: University of Texas-Press, 1993:iii-xi. Em formato eletrônico.

LÉVINAS, Emmanuel. Ética e infinito. Trad. João Gama. Lisboa: Edições 70, 2010.

. Entre nós. Ensaios sobre a alteridade. Trad. Pergentino Stefano Pivatto. Petrópolis: Vozes, 2009.

LIAPUNOV, Vadim. Prefácio do Tradutor da Edição Americana. In: Bakhtin, M.M.. Para uma filosofia do ato. Trad. da Ed. Americana Toward a Philosophy 
of the Act. Austin: University of Texas Press, por Carlos Alberto Faraco e Cristovão Tezza, 1993 (para fins didáticos).

PELIZZOLI, Marcelo. Notas para compreender Lévinas. In: Souza, R.T.; Farias, A.B.; e Fabri, M. (Orgs.). Alteridade e Ética. Obra comemorativa dos 100 anos de nascimento de Emmanuel Lévinas. Porto Alegre: Edipucrgs, 2008, pp. 273-291.

PONZIO, Augusto. A revolução Bakhtiniana. São Paulo: Contexto, 2008.

Prefácio. In: Bakhtin, M.M.. Para uma filosofía do ato responsável. Trad. Valdemir Miotello. São Carlos: Pedroejoaoeditores, 2010.

RUIZ, Castor B. Emmanuel Levinas, alteridade \& alteridades - questões da modernidade e a modernidade em questão. In: Souza, R.T.; Farias, A.B.; e Fabri, M. (orgs.). Alteridade e Ética. Obra comemorativa dos 100 anos de nascimento de Emmanuel Lévinas. Porto Alegre: Edipucrgs, 2008, pp. 117-148.

SAMPAIO, Maria Cristina Hennes. Vida e envelhecimento: uma re-leitura filosófica de Mikhail Bakhtin e Henri Bergson. In: Paula, L. de e Stafuzza, G. (Orgs.). Círculo de Bakhtin: Diálogos In Possíveis. V. 2, Série Bakhtin Inclassificável. São Paulo: Mercado das Letras, 2011, pp. 101-122.

. A propósito de Para uma filosofia do ato (Bakhtin) e a pesquisa científica nas Ciências Humanas. Bakhtiniana, V. 1, n. 1, 2009, pp. 42-56.

SOBRAL, Adail. Filosofias (e filosofia) em Bakhtin. In: Beth Brait (Org.). Bakhtin Conceitos-Chave. S.Paulo: Contexto, 2005, pp.123-150.

TAMINIAUX, Jacques. Prefacio. Contrapunto ao modo de prólogo. In: Schiffer, D.S.. La filosofia de Emmanuel Lévinas. Metafísica, Estética, Ética. Trad. Heber Cardoso. Buenos Aires: Claves, Perfiles, 2008.

ZAVALA, Iris. O que estava presente desde a origem. In: Brait, B. (Org.) Bakhtin, dialogismo e Polifonia. São Paulo: Contexto, 2009, pp.151-166. 